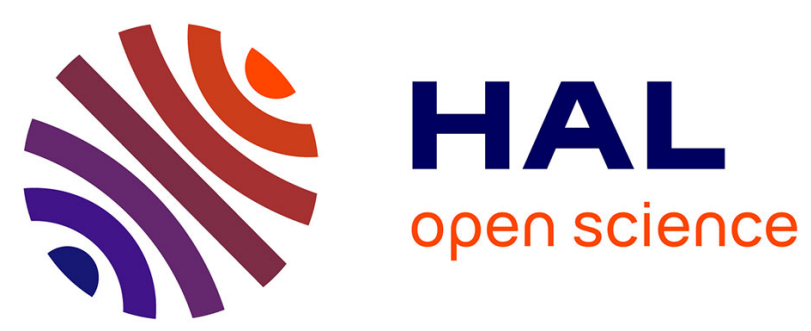

\title{
Modifications induced by sweeping and observed in quartz crystals according to their $\alpha 3500$-value
}

\author{
P. Zecchini, K. Yamni, B. Viard
}

\section{To cite this version:}

P. Zecchini, K. Yamni, B. Viard. Modifications induced by sweeping and observed in quartz crystals according to their $\alpha 3500$-value. Journal de Physique IV Proceedings, 1994, 04 (C2), pp.C2-189-C2-194. 10.1051/jp4:1994223 . jpa-00252491

\section{HAL Id: jpa-00252491 https://hal.science/jpa-00252491}

Submitted on 1 Jan 1994

HAL is a multi-disciplinary open access archive for the deposit and dissemination of scientific research documents, whether they are published or not. The documents may come from teaching and research institutions in France or abroad, or from public or private research centers.
L'archive ouverte pluridisciplinaire HAL, est destinée au dépôt et à la diffusion de documents scientifiques de niveau recherche, publiés ou non, émanant des établissements d'enseignement et de recherche français ou étrangers, des laboratoires publics ou privés. 


\title{
Modifications induced by sweeping and observed in quartz crystals according to their $\alpha_{3500}$-value
}

\author{
P. ZECCHINI, K. YAMNI and B. VIARD
}

Laboratoire de Cristallographie et Chimie Minérale, Université de Franche-Comté, 25030 Besançon cedex, France

\begin{abstract}
In order to check what sweeping can induce - in quartz material, two particular blocks have been studied. These crystals were chosen according to their $\alpha_{3500}$ infrared value, and so classified as standard quartz or HQ quartz. The different techniques, infrared spectroscopy, ICP chemical analysis, X-ray topography and etching have been used on the same samples before and after sweeping. The chemical analysis results show an effective migration of alkalis. This migration is different from a sample to the other but it remains sometimes very weak in both cases. The decrease of the number of the etch-pits and the length of the etchchannels has been verified in the swept part of the crystal comparably to the unswept part of the same crystal; the initial quality of the material appears to be an important parameter. X-ray topography shows that there is no modification by sweeping in the partition of the dislocations within both the crystals. Infrared spectroscopy reveals that the homogeneity of the crystals can be modified by sweeping. The measurements lead to some unexpected results which indicate that the sweeping cannot be considered as a routine process.
\end{abstract}

\section{INTRODUCTION}

To increase the quality of quartz resonators, the crystals used to cut them are generally swept. This treatment is performed or under vacuum or air or controlled atmosphere. During this operation, the crystal is placed in an electric field and heated. Then, there is a migration of the impurities and some modifications are induced within the crystal. According to the parameters used by the manufacturer during the sweeping process and the quality of the as-grown crystals, the results could be very different. Many workers have studied the effect of the sweeping and already used different techniques(1-13) but generally, the number of the techniques used on the same sample is limited. In order to add some informations to what happens during a sweeping process, two particular blocks, chosen according to their commercial infrared $\alpha_{3500}$ value, have been measured before and after sweeping, using many different techniques: infrared spectroscopy, X-ray topography, etching and chemical analysis. Then, by comparing all together the experimental results from all these techniques used on the same samples, a better way may be open to detect the sweeping induced modifications . 


\section{EXPERIMENTAL PROCEDURES}

The two crystals used have been cut as indicated in figure 1. The $A_{1}$ and $B_{1}$ parts have been swept. A 5 mm thick and a $1 \mathrm{~mm}$ thick $Y$-cuts are sliced in the $B_{1}$ and $B_{2}$ part, respectively for infrared study and $X$ ray topography. Then, the remaining parts are sliced in several $1 \mathrm{~mm}$ thick $Z$-cuts from the $Z$-face to the seed for the chemical analysis. A AT-cut is sliced in the $A_{1}$ and $A_{2}$ parts for etching.

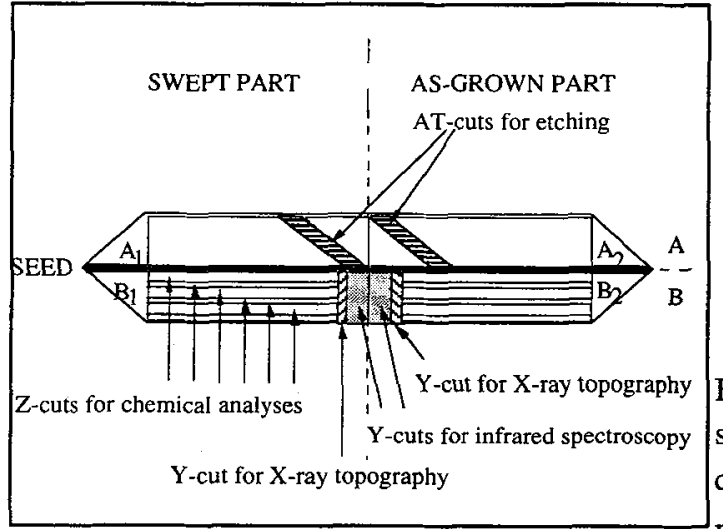

figure 1: cutting up of the crystals

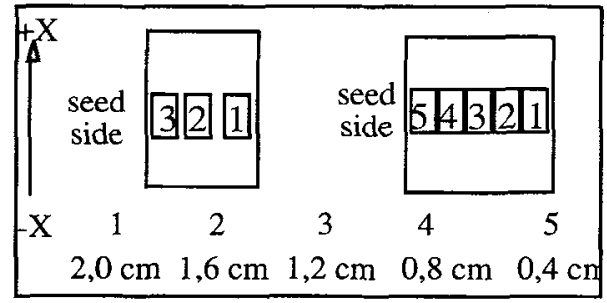

figure 2: positions of measurements

By using a double beam spectrometer, infrared study is performed or at room temperature for the calculation of the $\alpha_{3500}$ values at 3 or 5 beam positions along the $\mathrm{Z}$-axis, figure 2 , and also for the determination of the homogeneity of the crystals, or

at $85 \mathrm{~K}$, to measure the "s" and "e" absorption bands.

The chemical analyses are made by ICP (inductively coupled plasma).

The crystals have also been studied by X-ray Lang projection topography using the $(10 \overline{1} 0)$ reflection and the $\mathrm{Mo} \mathrm{K}_{1}$ radiation.

\section{EXPERIMENTAL RESULTS}

\subsection{Qualification of the crystals and evaluation of their homogeneity}

The $\alpha_{3500}$ values obtained are reported in table 1 .

Table 1: $\alpha_{3500}$ values of the as-grown crystals

\begin{tabular}{|c|c|c|c|c|c|c|c|}
\hline \multicolumn{3}{|c|}{ standard crystal } & \multicolumn{5}{c|}{ high quality (HQ) crystal } \\
\hline region 1 & region 2 & region 3 & region 1 & region 2 & region 3 & region 4 & region 5 \\
\hline 0,063 & 0,058 & 0,078 & 0,0238 & 0,0233 & 0,0232 & 0,0237 & 1,0229 \\
\hline
\end{tabular}

The variation of the $\alpha_{3500}$ value can be observed at 3 beam heights along the $\mathrm{X}$-axis, for many different positions along the $\mathrm{Z}$-axis, as indicated in figure 3 . Its evolution is given in the figure 4 for both the samples, before and after sweeping. The high-quality crystal is homogeneous in the $\mathrm{Z}$ - and $\mathrm{X}$-directions.

\subsection{Etching}

The figures 5 and 6 indicate that there is an equivalent number of etch-pits and

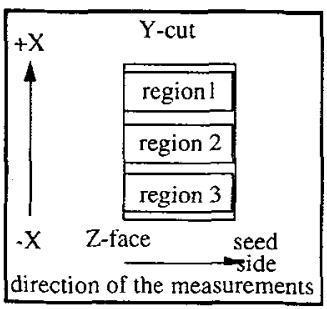
etch-channels in both the samples before the sweeping process even if they have 
a large different quality, but after, a larger decrease of them is observed in the high-quality sample than in the standard crystal. Indeed, 433 and 405 etch-pits $/ \mathrm{cm}^{2}$ are counted over the unswept crystals and only 261 over the standard crystal or 7 over the $\mathrm{H}$ Q one after the sweeping process. As expected, the length of the etch-channels decreases in both cases.

\section{3 .3 X-ray topography}

As shown in figure 7 , there is no effect of the sweeping on the dislocations. Some growth lines can be detected in the $\mathrm{Z}$ zone by this technique.

\subsection{ICP chemical analysis}

Each Z-cut was cut in two pieces, called "d" and "g" before sweeping and "Sd" and "Sg" after sweeping. The chemical analysis results are given in figure 8 , for the standard crystal and in figure 9 for the high-quality crystal. A very low migration of the alkalis is observed, and only in the best case, the lithium is removed.

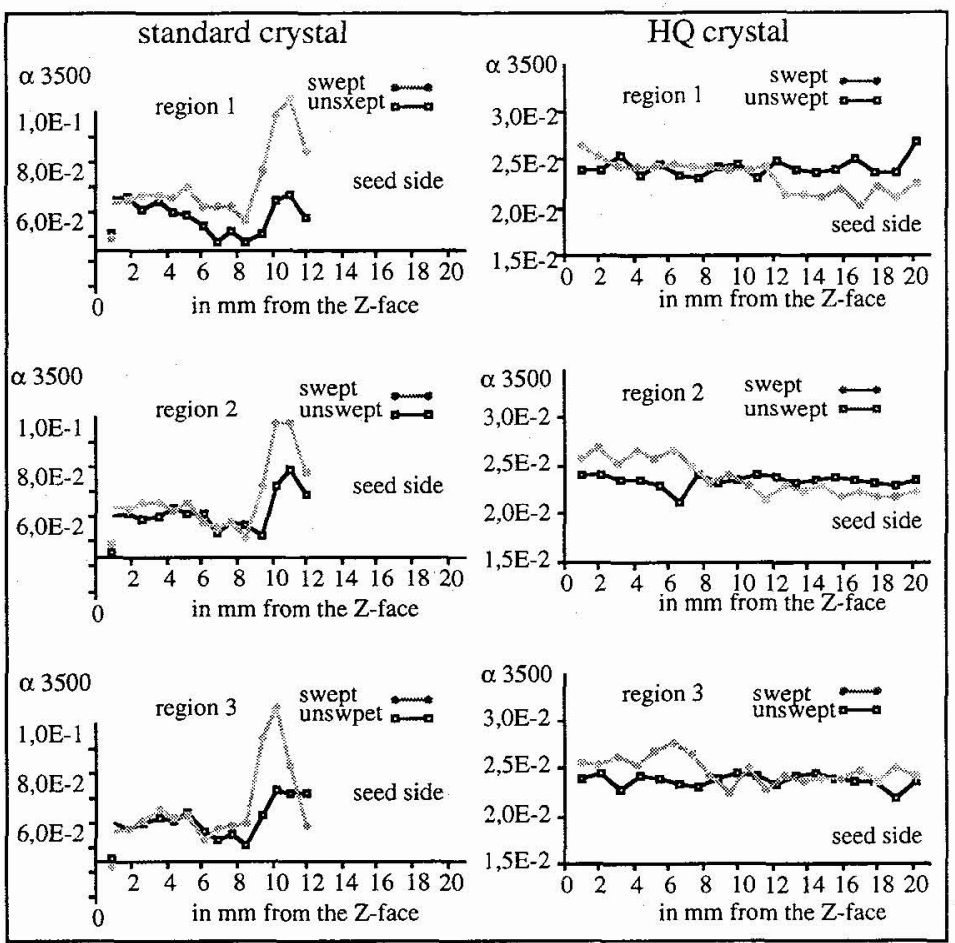

figure 4: evolution of the $\alpha$-value along the Z- and X-axes
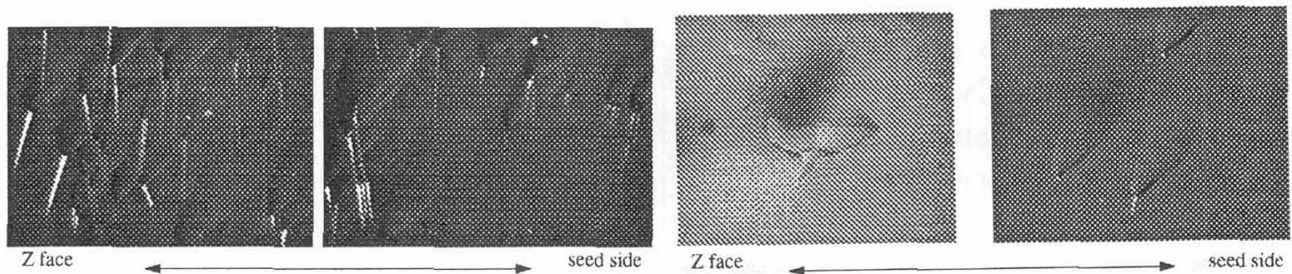

figure 5: etching results. On the left, unswept H Q crystal; on the right, swept H Q crystal.
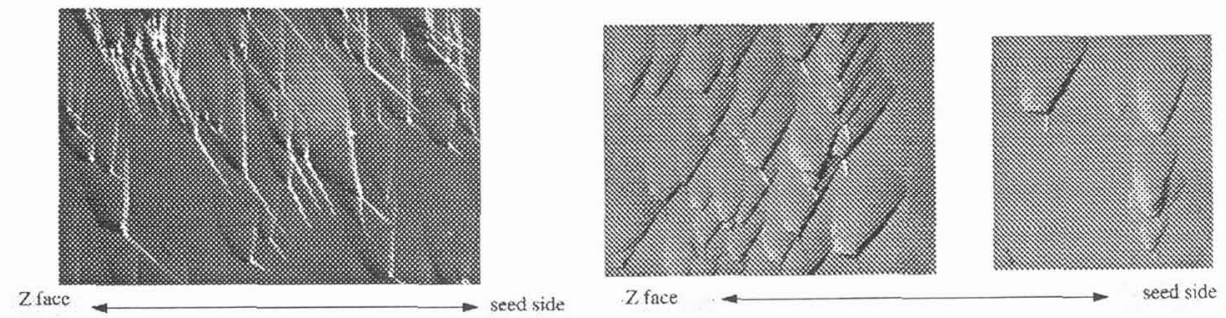

figure 6: etching results. On the left, unswept St. Q. crystal; on the right, swept St.Q. crystal. 


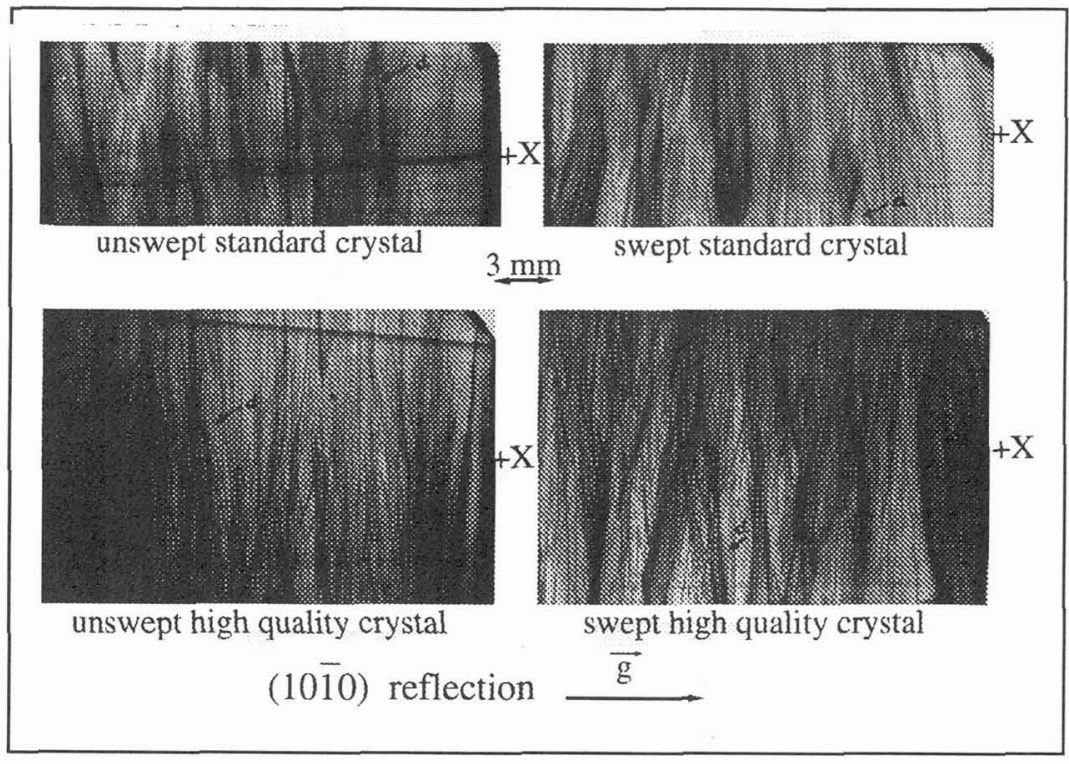

figure 7: X-ray topographies

\subsection{Infrared study at $85 \mathrm{~K}$}

The spectra obtained with the Y-cuts of both the samples, before and after sweeping, are given in figures 10 and 11 . The unswept samples are homogeneous in the $\mathrm{Z}$ - and $X$ - directions. The heights of the absorption bands are equivalent in a given sample and the better quality of the H Q crystal is well visible: the "s" absorption bands have a large lower intensity and only the " $s_{4}$ " and " $s_{2}$ "

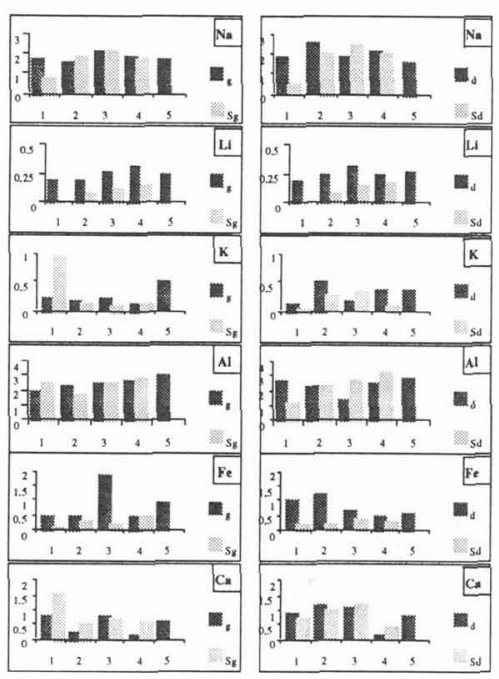

figure 8: analysis of the St. crystal

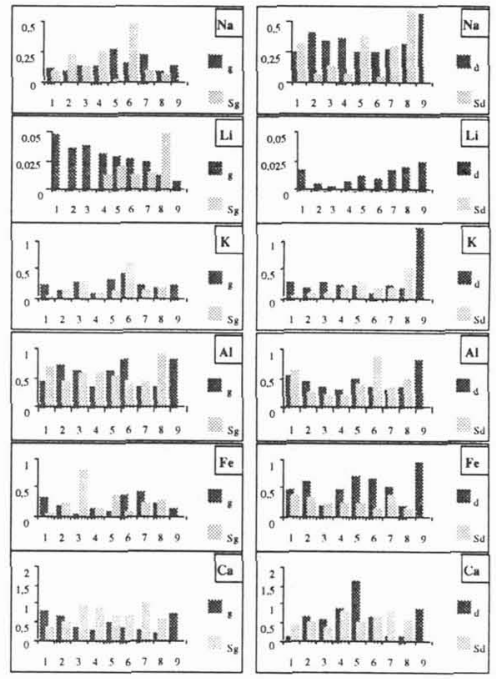

figure 9: analysis of the H.Q. crystal

bands are well detected. For the H Q crystal, after sweeping, the measurements indicates a large difference as well in the Z-direction than in the X-direction. Close to the seed, in the swept sample, there is no longer the " $\mathrm{s}$ " absorption bands. This band is still visible near the Z-face and in that part, the " $\mathrm{e}_{2}$ " is visible too. This difference appears also in the X-direction. For the standard quality crystal, the " $e_{2}$ " and all the "s" absorption bands are detected. The " $\mathrm{e}_{2}$ " absorption is well visible close to the $\mathrm{X}$ zone whereas it is only a shoulder, lower close to the $+\mathrm{X}$ zone than in the middle of the $\mathrm{Z}$ zone. 


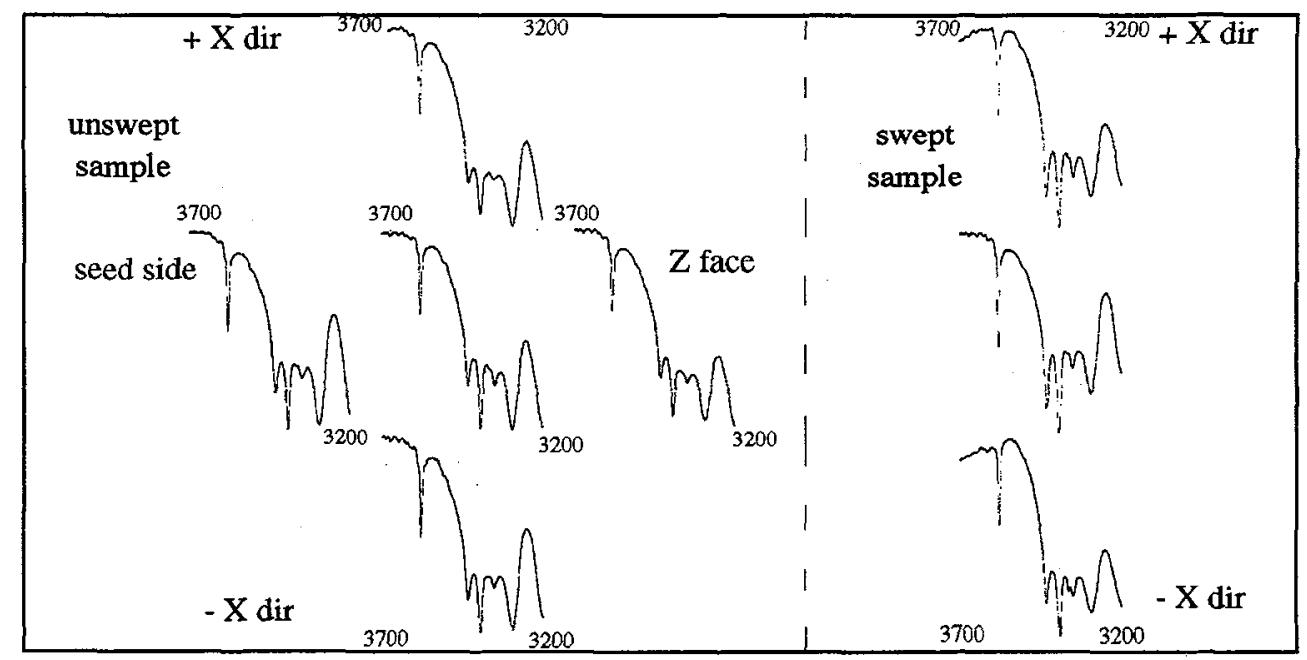

figure 10: infrared transmission spectra measured at $85 \mathrm{~K}$ along the $\mathrm{Z}$ direction or at different beam heights along the $\mathrm{X}$-axis for the unswept and swept standard quartz crystal

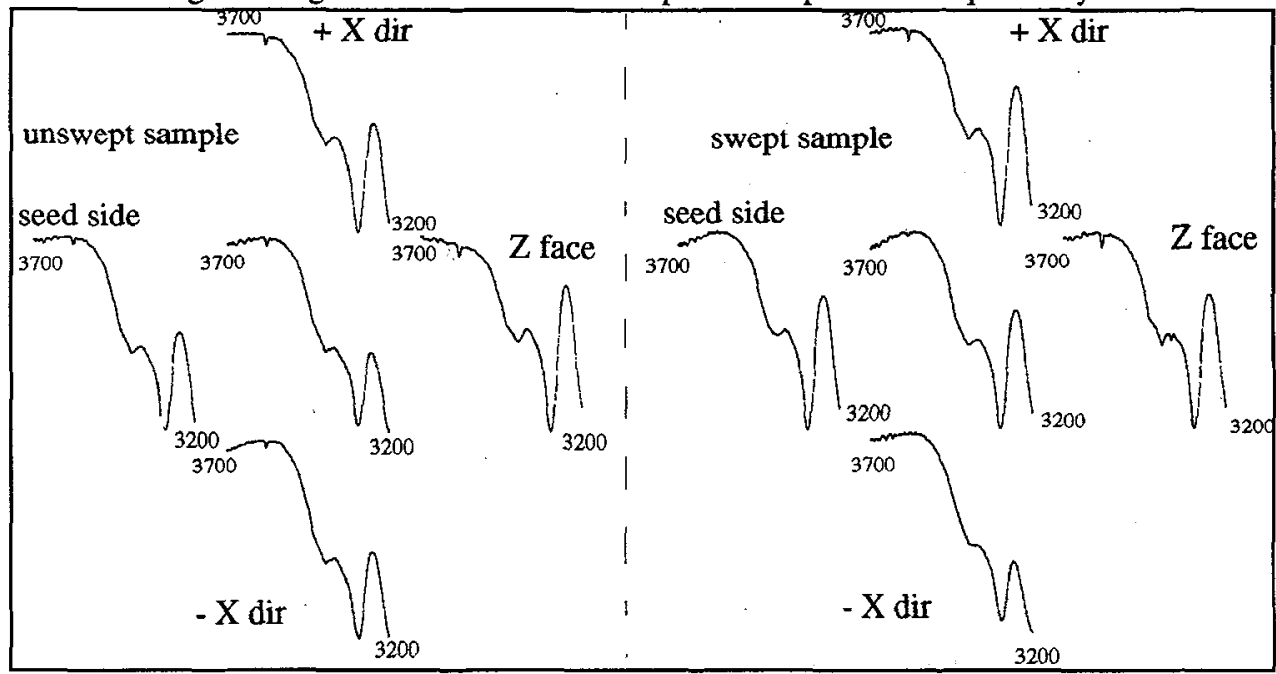

figure 11: infrared transmission spectra measured at $85 \mathrm{~K}$ along the $\mathrm{Z}$ direction or at different beam heights along the X-axis for the unswept and swept $H$ Q quartz crystal: .

\section{CONCLUSION}

For this study, many techniques have been used to qualify a standard quality quartz crystal and a high quality quartz crystal before and after sweeping.

The chemical analyses of the unswept crystals show a low rate of all the classical impurities in the $\mathrm{H} Q$ crystal and an equal partition within the crystal in both Z- and X-directions. For the standard quality crystal, higher amounts of aluminium and sodium are measured. The distribution of the impurities varies in larger proportions within this last crystal. These results have been confirmed by infrared spectroscopy at room temperature and at $85 \mathrm{~K}$. 
In both the as-grown crystals, the etching shows an equivalent number of etch-pits and etch-channels and the $\mathrm{X}$-ray topography technique indicates a large concentration of dislocations and some growth bands in the $\mathrm{Z}$ zone.

After sweeping, the expected results such as no change in the distribution of the dislocations or a large diminution of the number of the etch-pits and etch-channels, larger for the HQ crystal than in the standard crystal are observed. In both the crystals, the length of the remaining etch-channels has decreased. The chemical analyses show a migration of the alkalis but only the lithium has been removed. Infrared spectroscopy indicates no longer homogeneous crystals. This result could give the explanation of some results obtained for the quality of the resonators cut in the swept and in the unswept H Q material (14).

These results show that the sweeping cannot become a routine process even if all the same experimental conditions are ever applied. The quality of the swept crystal can change in such a way that the modifications are sometimes unexpected. So, each industrial swept crystal must be controlled before using.

\section{References}

[1] KATS A. , Philips Res. reports, 17 (1962) 133-195 and 201-279.

[2] KREFFT G.B., Radiation Effects, 26, (1975) 249-259.

[3] KING J C , US patent 3,932,777, (1976)

[4] LIPSON H.G. , EULER F. , ARMINGTON A.F. ,'Low temperature infrared absorption of impurities in high grade quartz", 32nd Annual Frequency Control Symp.1978, pp.11-23

[5] TOULOUSE J., GREEN E.E. and NOWICK A.S. ,"Effect of alkali ions on electrical conductivity and dielectric loss of quartz crystals", 37th Annual Frequency Control Symp. 1983, pp.125-129

[6] LIPSON H.G. , KAHAN A. and O'CONNOR J , "Aluminum and hydrogen defect centers in vacuum swept quartz", 37th Annual Frequency Control Symp. 1983, pp. 169-173

[7] LIPSON H.G. and KAHAN A., IEEE Transactions on Nuclear Science, NS-31, n6 (1984) 1223 1229

[8] GUALTIERI J.G. , "The influence of temperature and electric field on the etch-channel density in swept cultured quartz", 39th Annual Frequency Control Symp.,1985, pp.247-254

[9] BALASCIO J.F. and ARMINGTON A.F. , “ Developmental results for the production of high quality quartz “, 40th Annual Frequency Control Symp.1986, pp.70-76

[10] MARTIN J. , "Electrodiffusion or sweeping of ions in quartz", 41st Annual Frequency Control Symp.1987, pp.167-174

[11] HANSOM W. ,'Transmission X-ray topography of single quartz crystal using white beam synchrotron radiation " 41 st Annual Frequency Control Symp.1987, pp.228-235

[12] ZARKA A., SEBASTIAN M. and CAPELLE B., "X-ray topography study of vacuum swept quartz crystal", 42nd Annual Frequency Control Symp.,1988 pp.208-209

[13].BIGNON O. and BROTTIER B. , "Etch-channel in quartz monocrystals. Factors of influence", 4th European Frequency and Time Forum 1990, pp.609-616

[14] BOY J.J. , ZECCHINI P. and VIARD B. , "Synthetic quartz material characterisations. Connections with the quality of an AT-cut resonator"., 5th European Frequency and Time Forum 1991, pp.129-135 